\title{
Preschoolers' different ways of structuring part-part-whole relations with finger patterns when solving an arithmetic task
}

\author{
Angelika Kullberg $^{1}$ (1) $\cdot$ Camilla Björklund $^{2}$
}

Accepted: 17 December 2019 / Published online: 21 December 2019

(c) The Author(s) 2019

\begin{abstract}
In this paper we report on findings from a study of 5-to-6-year-old children's ways of structuring part-part-whole relations using finger patterns. We focused our analysis on data from interviews with 28 children who during their last year of preschool learned to enact a structural approach. We used this data set to analyze their different ways of structuring a task with one part unknown, and what constitutes the ability to structure the task in a conceptually powerful way. The way children structure number relations was interpreted as being related to how they experience the task at hand. We identified some ways of structuring as being more powerful for future learning, particularly those that facilitate the child in experiencing parts and the whole simultaneously. We suggest that there are three aspects that children need to discern in order to structure the task successfully in both the short and the long term: what constitutes the whole, the parts within the whole, and finger patterns as a representation of the cardinality of a set. The pedagogical implications are that attention to children's ways of experiencing the number relations in arithmetic tasks gives clues to why some children develop powerful strategies, and how to support children in their learning to solve arithmetic tasks.
\end{abstract}

Keywords Part-part-whole relations $\cdot$ Preschool $\cdot$ Structuring $\cdot$ Addition and subtraction $\cdot$ Variation theory

\section{Introduction}

In this paper we direct attention to preschool children's ways of structuring part-part-whole relations of numbers in arithmetic tasks. This interest stems from the extensive field of research that has observed the benefits of developing a structural approach to arithmetic problem solving. Resnick (1983), for instance, argued that "Probably the major conceptual achievement of the early school years is the interpretation of numbers in terms of a part and whole relation. With the application of a Part-Whole schema to quantity, it becomes possible for children to think about numbers as composition of other numbers" (p. 114). Numbers, and addition and subtraction tasks, constitute part-part-whole

Angelika Kullberg

Angelika.Kullberg@gu.se

1 Department of Pedagogical, Curricular and Professional Studies, University of Gothenburg, Box 300, 40530 Gothenburg, Sweden

2 Department of Education, Communication and Learning, University of Gothenburg, Box 300, 40530 Gothenburg, Sweden relations, and experiencing these relations has also been described by others as critical for the development of arithmetic skills (Cheng 2012; Mulligan and Mitchelmore 2009), as it allows the child to make use of powerful strategies such as commutativity $(a+b=b+a)$, decomposition $(c=a+b)$ and the complement principle $(\mathrm{a}+\mathrm{b}=\mathrm{c}$ then $\mathrm{c}-\mathrm{a}=\mathrm{b})$. The use of such a structure is believed to facilitate arithmetic problem solving by eliminating unnecessary efforts, such as counting strategies (Baroody et al. 1983).

Enacting a structuring approach is based on numerical reasoning about quantities of parts and the whole simultaneously (Davydov 1982; Neuman 2013; Schmittau 2003), which induces an understanding of units and number relations. There is research support that a structural approach to arithmetic problem solving is powerful and well worth teaching in early arithmetic education. Nevertheless, the results of educational research suggest that preschool children have difficulties learning part-part-whole relations or applying such insights in arithmetic tasks (Baroody and Purpura 2017). There are, however, few studies on how young children develop such capabilities (Mulligan and Mitchelmore 2009), and the quality and differences in performance of children. 
In an earlier study (Björklund et al. 2019) we investigated 4-5-year-olds' spontaneous use of fingers in arithmetic problem solving and found that children who used a strategy of counting single units as their only strategy were not able to solve simple arithmetic tasks while others who instantly showed finger patterns or created finger patterns by counting and creating finger patterns, thus structuring numbers on their fingers, were more successful. Our analysis showed that these children had different ways of understanding numbers that seemed to affect their arithmetic performance. The study raised our awareness that it may not be the strategy use or finger use in particular that tell us about a child's skills in solving arithmetic tasks; there may be alternative ways of interpreting children's number knowledge, as seemingly similar use of fingers induces very different outcomes when solving arithmetic tasks. Thus, we chose to take a closer look at the ways children enact a structural approach when solving arithmetic tasks, in order to gain more insight into how different enactment of creating finger patterns reveals different ways of understanding the meaning of numbers. In this paper we therefore look more closely at the quality and differences in performance when children structure part-part-whole relations when solving a task with one part unknown. The aim was to gain a deeper understanding of what it means for preschool children to structure part-partwhole relations when solving arithmetic tasks, and more specifically what is entailed in different ways of structuring in terms of powerful ways of understanding and handling tasks. Our research questions were as follows: (1) In what ways do children structure a task with one unknown part? and (2) What constitutes the ability to structure the task in a conceptually powerful way? In order to answer these questions, we conducted observations of preschool children's ways of encountering the task "You have three glasses, but are going to set the table for eight people; how many more glasses do you need?" and particularly how they enact a structural approach, e.g., with the aid of finger patterns.

\subsection{Approaches to early addition and subtraction learning}

Formal education is often based on counting and counting strategies as the starting point for the development of addition and subtraction skills (Carpenter and Moser 1982; Fuson 1992; Verschaffel et al. 2007). This entails that children are taught to "count all" objects in order to determine a quantity, and develop strategies such as "counting from the first" addend, and further on "counting from the largest" addend (Fuson 1992). Using counting to solve a task requires, for example, that when the second addend is larger than 3 or 4 , children need something (e.g., their fingers) to keep track of the number words that are said beyond the first addend (Fuson 1982; Carpenter and Moser 1983). A counting (or operational) approach uses counting as the basis for the acquisition of arithmetic skills, and from this the subsequent development of an awareness of structure, e.g., in part-part-whole relations. However, counting strategies involving counting single units entail that the child does not have to see the counted steps as part of the counted number (Steffe and Cobb 1988). This approach may thereby not necessarily prepare children for experiencing part-partwhole relations of numbers. Hunting's (2003) studies of preschool children inform us that when children change focus from counting single units to identifying them as a group or unit, it makes a major difference in their developing number knowledge. Later studies suggest that early-learned counting strategies involving counting single units can even impede children's learning of more advanced strategies such as decomposition, since some children continue to use single unit counting strategies that have worked well on easier tasks even in tasks that would require other ways of handling numbers, particularly considering numbers' part-part-whole relations (Cheng 2012; Geary et al. 2013; Neuman 2013).

Subitizing is often mentioned as a foundational ability to recognize exact (small) numerosities, as an instant process of determination, without counting. Many frameworks describing number knowledge and arithmetic skills assume this cognitive process to be a starting point for capabilities such as cardinality, unitizing and arithmetic skills (Clements et al. 2019). Conceptual subitizing (Clements 1999) is furthermore significant in that it frames how children through decomposing and composing units of units are able to handle larger sets as additive, without relying on counting single units. This can also be related to what Steffe (1994) describes as children experiencing a set of items as one numerical object (a composite unit the numerosity of which is greater than one). Understanding number as composite units is a pre-requisite for decomposing and re-grouping strategies, or in other words, for experiencing the structure of an arithmetic task. The subitizing process, since it includes basic ideas of cardinality, unitizing and of part-whole relations, thereby relates also to elementary arithmetic (Clements et al. 2019).

When children are structuring numbers, in contrast to counting single units, they experience the part-whole relations of numbers in the mathematical problem and often seem to experience numbers as composite sets (Ahlberg 1997). Ahlberg described that when a child structures a task,

The child does not use their fingers to count on. Instead they structure their fingers in a part-part-whole relation, thus grasping the numerosity of the numbers by seeing (...) When children handle numbers by structuring they do not count on the number sequence in order to keep track of the numbers, but rather structure the numbers in the problem in parts and the whole in order to arrive at an answer. (p. 70) 
Similarly, Marton and Neuman (1990) found strategies in which seven-year-old children when dealing with problems like $\mathrm{a}+\ldots=\mathrm{c}$ carried out,

an analyzing (structuring), rather than a counting, procedure. The children analyzed a concrete or visualized number, which was grouped in such a way that it was possible to subitize (i.e., its numerosity could be immediately perceived). In their analysis, they could detect new ways in which the parts could be related to each other or to the whole. (p. 65)

Children's awareness of structure has been debated lately and is asserted to be of vital importance for mathematics learning (Lüken 2012; Venkat et al. 2019). According to Venkat et al. (2019), knowledge about structure can be summarized as an awareness of a network of basic and general relations. Emergent structures, Venkat et al. suggest, can be observed among younger children when they are able to analyze and discern local relationships, which will eventually allow them to identify more general mathematical relations and properties, such as commutativity and compensation.

\subsection{Finger use in arithmetic learning}

Research from different disciplines (e.g., Berteletti and Booth 2015; Crollen et al. 2011) has shown that the development of arithmetic skills may be related to the use of fingers and in particular the representational use of fingers (Reeve and Humberstone 2011). Finger use is however not an innate ability since there is a broad variety in how fingers are used in different cultures (Bender and Beller 2012; Ifrah 1985). Contemporary research furthers our understanding of children's abilities to use finger representations as rather being determined by the context and task properties (Sinclair and Pimm 2015).

Neuman $(1987,2013)$ raised an essential point concerning finger use in arithmetic learning, that focus should be on children's ways of using fingers for arithmetic computation, not whether fingers should be used or not when learning arithmetic. Fingers are for instance an instrumental aid to keep track when reciting the number sequence or to keep track of counted items (Fuson 1988). Fingers can however also be used to structure numbers so that the relation between and within numbers becomes visiblea whole hand can be seen as two and three fingers but also as four and one finger together. Baroody (1987) made efforts to systematically describe how young children use their fingers, and particularly pointed out the benefits of structuring numbers with finger patterns as efficient "shortcuts". Recent studies also bring to the fore that children's ways of using their fingers may be an expression of how numbers are experienced with implications for their numerical reasoning skills (Björklund et al. 2019). In this paper we take this conjecture as our departure point in aiming to study the ways children structure numbers as expressions of the meaning numbers have for them.

\section{Theoretical framework}

To reveal how children experience part-part-whole relations when structuring an oral task with one part unknown $\left(3+_{-}=8\right)$, we used the variation theory of learning (Marton and Booth 1997) as a theoretical framework. The variation theory of learning emanates from phenomenography (e.g., Marton 1981; Marton and Neuman 1996), which investigates how the same phenomenon (e.g., numbers) can be experienced differently by different learners, which highlights the different meanings things have for peoplein our case what numbers mean to preschool children and how adding and subtracting make sense to them. According to the theory, how people act is in accordance with what they see. In order to learn to do something, such as solving a problem in a certain way, one has to learn to see something in a particular way. A group of preschool children will thereby show a variation in how they handle arithmetic tasks that can be connected to how they experience numbers. Furthermore, different ways of experiencing numbers are due to differences in the discernment of aspects related to numbers. A fundamental idea in the variation theory of learning is that for each learning object there are some necessary aspects that the learner needs to discern (Marton 2015). For example, in order to develop arithmetic skills, the child needs to experience the first ten natural numbers in terms of, e.g., ordinality, cardinality, and part-part-whole relations. How children act and answer when trying to solve an addition or subtraction task, for instance, is connected to whether they discern these aspects, or whether some aspect is undiscerned and thus affects how the child experiences numbers and what it is possible to do with the numbers in a task. In sum, the different ways of structuring identified in this paper are expressions of different ways of seeing and understanding numbers in the task at hand. The theoretical framework guides us in interpreting how a child's way of structuring numbers is an expression of how the child experiences the meaning of the numbers and their role in the arithmetic task. Thus, we observe children's strategies but interpret them as expressions of ways of experiencing numbers. This is an alternative way of describing children's numerical competence, which sheds light not only on differences in enactment when solving an arithmetic task, but also on differences in ways of understanding or 'seeing' the task. 


\section{Method}

Our main aim is to direct attention to what it means to structure part-part-whole relations as finger patterns when solving arithmetic tasks in the early years. In the FASETT ${ }^{1}$ project we investigated preschool children's learning of number and arithmetic skills, and interviewed 103 5-year-olds three times over a prolonged time period (mean age at interview I: 5 years 3 months; interview II: 5 years 11 months; interview III: 6 years 11 months). The participating children were of mixed socio-economic backgrounds and came from three suburbs of a large Swedish city. They were all Swedishspeaking and had attended preschool for several years (the attendance rate in Swedish preschool is very high; most 2-5-year olds are enrolled in some pedagogical practice). Swedish preschool is voluntary and the national curriculum provides guidelines for content areas such as mathematics but does not outline how to teach certain mathematical content. Thus, the children may have encountered different ways of using fingers as aids in numerical problem solving.

In this particular study we first selected those children who scored less than $15 \%$ correct on arithmetic tasks in the first interview, giving us 58 children. The rationale for selecting children with little pre-knowledge was our interest in their emergent structuring. In their first interview, many children showed that they experienced some aspects of numbers, ordinality and/or cardinality, but were unable to coordinate these necessary aspects and did not experience a part-part-whole relation of numbers. If this is the case, children cannot solve the tasks since they do not see the numbers as composite sets that have numerical relationships to each other (for more details about this analysis see Björklund et al. 2019; Björklund and Runesson Kempe 2019, accepted). Thus, the interviews revealed a variety of ways of experiencing numbers among the children, with implications for their success in solving tasks. Four different ways of experiencing numbers were identified among the children: Un-coordinated handling of numbers (estimating or guessing), Counting (single units only), Structuring (by means of fingers), and Known number facts (rapid mental calculation). Included in the observations were also children who in the first interview gave No answers and who received No question (if answers were incorrect on two straightforward addition and subtraction items, $2+5$ and $10-6$, due to ethical concerns the child did not receive what we considered to be a more demanding item $3+_{-}=8$; see Carpenter and Moser 1983 p. 10). No child in the sample enacted a structural approach in the first interview. We then selected

\footnotetext{
${ }^{1}$ FASETT-The ability to discern the first ten numbers as a necessary ground for arithmetic skills - is a research project funded by the Swedish Research Council.
}

observations from the second interview eight months later in which children enacted a structural approach in one specific task ( $\mathrm{n}=28$ ). Category inclusion criteria for Structuring is based on the main project's emphasis on finger use in early mathematics learning and more specifically on Ahlberg's (1997) description that the child does not use fingers to count on the number sequence in order to keep track of the numbers but instead to structure his or her fingers in a partpart-whole relation in order to arrive at the answer. Children who expressed knowing number facts were excluded as they mostly did not give sufficient explanations for their correct answers, which thereby would not provide us with data for their ways of structuring. Not all of the children in the selected 28 observations provided a correct answer.

\subsection{The interviews}

All children's parents or legal guardians had given their written consent for the children to participate in the interviews. The interview was comprised of several items within the number range 1-10, and lasted about 15-20 min. The interviews were conducted by members of the research team. The tasks were presented orally, and during the interviews no numerals or manipulatives other than fingers were used. However, the children were encouraged to use their fingers if they wanted to. If the child did not want to answer, or gave an answer that was too improbable on two consecutive items, due to ethical concerns the interviewer did not continue with more tasks of a similar type. All interviews were video-recorded to ensure reliability in the coding and analysis.

We report here on one of the eight orally given addition and subtraction items: 'You have three glasses, but are going to set the table for eight people; how many more glasses do you need?' ( $\left.3++_{-}=8\right)$. This was considered an item that could not easily be solved by counting single units, but instead was assumed to require structuring and allowing for different ways of structuring, for its solution.

\subsection{Analysis}

In this study we analyzed how children structure an arithmetic task with one part unknown, to find out what constitutes the ability to structure the task in a conceptually powerful way. Variation theory provides the theoretical framework for how the different ways of structuring are seen as expressions of different ways of seeing and understanding the task at hand, which is assumed to have implications for the success rate of children and further development of their arithmetic skills. The unit of analysis is children's verbal utterances and actions, e.g., with fingers, when solving the task.

In the process of analysis, we first repeatedly watched the 28 video recordings and transcribed verbatim how the 
Table 1 Ways of structuring

\begin{tabular}{lc}
\hline Categories & $n=28$ \\
\hline $\begin{array}{l}\text { Instantly showing finger pattern sets without counting single } \\
\text { units }\end{array}$ & 7 \\
Instantly showing finger pattern sets and counting single units & 21 \\
Counting on the unknown part on separate hand & 9 \\
Counting on by partitioning the unknown part, on separate & 12 \\
hands & \\
\hline
\end{tabular}

children enacted their structuring when solving the 'set the table' task. We then identified two main categories of ways of structuring: Instantly showing finger patterns as sets, and Instantly showing finger pattern sets and counting single units. These categories had earlier been found also in the previous study by Björklund et al. (2019). Second, a more fine-grained analysis identified differences within these two main categories in terms of how children enacted the structuring to solve the task at hand, that is, in what ways the children composed the parts and the whole given in the task, for instance by counting on or instantly adding a whole finger pattern set (such as the whole hand), and furthermore whether the child operated primarily from one hand or used both hands. These different ways of enacting were then further analyzed in terms of the way of experiencing the task of which the enactment could be an expression. In line with our theoretical framework, we observed that certain ways of acting were expressions of more advanced ways of experiencing numbers and of the child thereby discerning more of the necessary aspects of the task. Then, when considering the task at hand we were able to conclude how certain ways of acting liberated more or less powerful ways of structuring the part-part-whole relations and supported the child in solving the task. According to variation theory, certain ways of acting are expressions of some aspects of the task at hand being discerned, while other aspects may not yet have been discerned. The more aspects manifested by the child-and discerned by the researchers-liberate what the child is able to do with the task at hand.

\section{Results}

In our analysis of children's ways of structuring, we found two main categories: Instantly showing finger patterns as sets, and Instantly showing finger pattern sets and counting single units, the latter further including two sub-categories of ways to enact the structural approach (see Table 1). These are in the following discussion described and problematized in terms of how the structuring is enacted and what constitutes the respective ways of structuring when solving the task 'You have three glasses, but are going to set the table for eight people; how many more glasses do you need?' $\left(3+{ }_{-}=8\right)$.

\subsection{Instantly showing finger pattern sets without counting single units}

In our sample we found seven instances of children structuring numbers on their fingers without counting single unitsthey created a structure of composite sets to solve the task. These children created composite sets of numbers as finger patterns and all of them were fluent in this act, producing a structure on their fingers from which they instantly 'saw' the answer (see Fig. 1). The excerpt below shows how Hannah, who by simply looking at her fingers could see the given part (3) and the whole (8) and thereby determine the unknown part (5) (see Fig. 1):
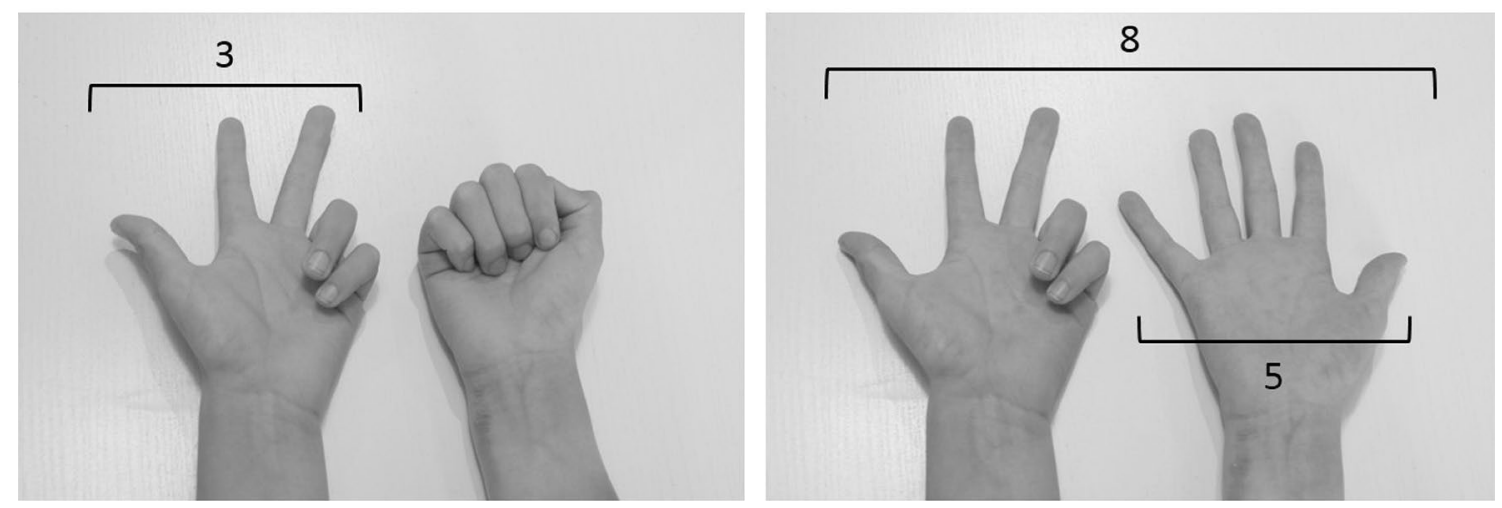

Fig. 1 Illustration of how a child structures the part-part-whole relationship without having to count single units by first showing the given addend (3) and then producing the whole (8), and thereby recognizing the missing addend as the whole hand (5) 


\begin{tabular}{l}
\hline $\begin{array}{l}\text { Hannah: Three glasses and } \\
\text { eight are going to eat, how }\end{array}$ \\
many more. Three (shows \\
thumb, index, middle finger on 5 in the 8. \\
her left hand) and eight (puts \\
her whole right hand on the \\
table; looks at her hands) Five \\
more.
\end{tabular}

What characterizes this way of structuring is that the child instantly creates the first heard addend (3) and then the whole (8) by including the first addend in the whole, simultaneously. The three fingers constituting the first addend are thereby seen as a part of the whole eight. This way of seeing 'the 3 in the 8 ' also makes her see the unknown part, 'the 5 in the 8 '. Thus, numbers are perceived as composite sets, and are related in a part-partwhole fashion that helps her see the answer without having to count. The task at hand does help her to see the answer easily, since the second addend (5) can be recognized as a whole hand. Nevertheless, structuring in this way demands attention to how parts and the whole are related, and most importantly that parts are included in the number that constitutes the whole.

As discussed above, we have drawn the conclusion that experiencing how parts are included in a whole in a partpart-whole relationship is an important aspect that is critical for structuring a task of composite sets. The following excerpt shows one child (Sofia) who did not solve the task even though she enacted a structural approach, because she lost track of the whole and treated the task as if the whole were 10 instead of 8 :

\begin{tabular}{|c|c|}
\hline $\begin{array}{l}\text { Sofia: (shows index, middle and } \\
\text { ring fingers on her right hand } \\
\text { and keeps all fingers on her left } \\
\text { hand folded, looks a moment } \\
\text { at her hands) I need to bring } \\
\text { seven. } \\
\text { Interviewer: How did you do } \\
\text { that, show me, first you } \\
\text { showed three there (imitates } \\
\text { the child's finger pattern), how } \\
\text { many do I need to bring in } \\
\text { order to make eight? How } \\
\text { did you do it then? } \\
\text { Sofia: It's seven (looks at the } \\
\text { interviewer's hands), all these } \\
\text { (touches the interviewer's five } \\
\text { folded fingers on the left hand } \\
\text { and the folded thumb and little } \\
\text { finger on the left hand). }\end{array}$ & $\begin{array}{l}\text { Shows three and simultaneously } \\
\text { relates it to the whole ten com- } \\
\text { posed of the rest of the folded } \\
\text { fingers. Sees the unknown part } \\
\text { as } 7 \text { on her hands. } \\
\text { Incorrect answer-uses } 10 \text { as the } \\
\text { whole. }\end{array}$ \\
\hline
\end{tabular}

Our conclusion is that it is crucial that children not only experience numbers as parts of larger numbers, but also perceive the whole as specific to the task within which the two addends are to be found. When children fail to perceive the correct whole simultaneously with the parts they may very well structure part-part-whole relationships, but end up with wrong answers (see Sofia, above). The enactment, then, has one number (shown as a finger pattern of 10 in the example above) foregrounded, but not the two numbers presented in the task ( 3 and 8 ).

Our sample contained one instance of structuring that did end up with a correct answer even though the child did this by structuring in a distinctly different way, as shown in the excerpt below. Benjamin uses another way of composing and re-grouping between the parts, adding one unit (finger) to one set and then another unit (finger) to the other set, then making use of a structure composed by the doubles " 3 and 3 " and "4 and 4".

\begin{tabular}{|c|c|}
\hline $\begin{array}{l}\text { Benjamin: Three (shows the } \\
\text { thumb, index, middle fingers } \\
\text { on his left hand) then it's eight } \\
\text { (unfolds little, ring, middle fin- } \\
\text { gers on his right hand, holding } \\
\text { the hands close together) three } \\
\text { more. Or I got three so it's } \\
\text { going to be (pauses and looks } \\
\text { straight ahead) four more. } \\
\text { Three and it'll be, or no it'll } \\
\text { be five more because then } \\
\text { this is four here (unfolds ring } \\
\text { finger on his left hand) and } \\
\text { four here (unfolds all but the } \\
\text { thumb on his right hand) }\end{array}$ & $\begin{array}{l}\text { Sees simultaneously } \\
3 \text { and } 8 . \text { Makes use of doubles } \\
(4+4) . \text { Moves units between } \\
\text { the parts. } \\
\text { Correct answer. }\end{array}$ \\
\hline
\end{tabular}

Benjamin seems to recognize 4 on one hand and 1 on the other as one composite set $(4+1)$, which leaves the first addend (3) as one set. The whole (8) is emphasized only in the beginning, when he creates a pattern of 3 on his right hand as he starts grouping the parts within the whole on his fingers. He creates a structure composed of two parts (using doubles), 4 and 4, to which he can relate the numbers in the task.

\subsection{Instantly showing finger pattern sets and counting single units}

Most of the children $(n=21)$ who enacted a structural approach did so by both counting to create a set (represented as a finger pattern) and instantly showing numbers represented as composite sets on their fingers without counting (finger patterns), in the same act. Most of them managed to solve the task. In general, we can see that all but one of the children in this category started with the first given addend (3). This is not surprising since the semantic structure of the task is that you first have a set of three, presented orally, and then you are given the information that there are eight people coming. And lastly, the question is posed as to how many more glasses (than the three) you need to get. In order to solve the task, it is 

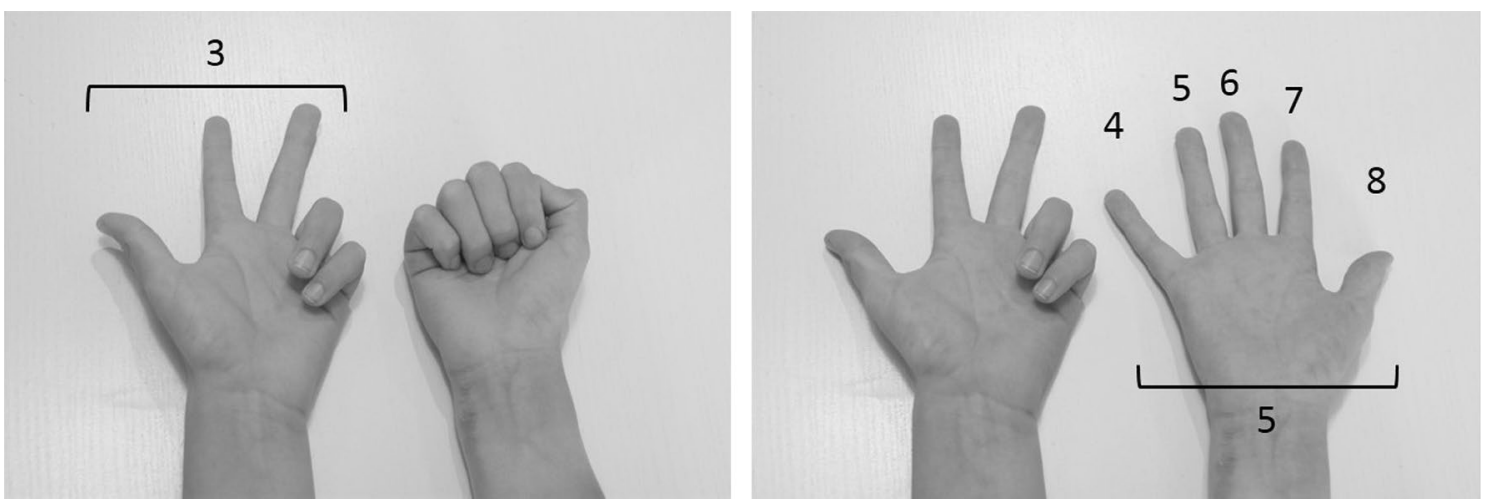

Fig. 2 Illustration of a child seeing the first addend as a unit of 3, 'counting on' to 8 on the other hand, and recognizing that the other addend is 5 (whole hand)

important to establish of what the whole is constituted, and what the part is, thus creating a structure of parts and the whole. Two children in our sample did not see the whole and the given part simultaneously, and thus lost track of the missing part, for example Peter in the excerpt below:

\begin{tabular}{l}
\hline $\begin{array}{c}\text { Peter: One, two (unfolds left } \\
\text { Creates the known part (3) by } \\
\text { thumb and index finger) and }\end{array}$ \\
$\begin{array}{c}\text { Creates the missing part by count- } \\
\text { then I need to get... }\end{array}$ \\
$\begin{array}{l}\text { Interviewer: Three at first, } \\
\text { ing on one finger at a time from } \\
\text { three glasses. }\end{array}$ \\
Peter: Three glasses (unfolds the \\
left middle finger as well) and \\
then I'll get one, two (unfolds \\
the ring and little finger) three, \\
four, five, six (unfolds one \\
finger at a time on his right \\
hand) maybe six more? (shows \\
the interviewer nine unfolded \\
fingers).
\end{tabular}

In the excerpt above, Peter is solving the problem by 'counting on'. What we can conclude is that he and the other child who 'counted on' in a similar way failed to find the answer because they lost track of how many units they needed to add to get the whole. Peter's verbal expressions reveal a rather empirical interpretation of the task, as he first creates the given part (3) and then says "then I need to get..." followed by a single counting act to add units. It does not seem as if he is experiencing numbers as related in a part-part-whole fashion, which hinders him in figuring out when to stop counting and adding on units to the given part.

While most of the children did perceive the parts and the whole simultaneously, how the structure was created differed among them. Discerning what the parts and the whole are simultaneously seems to be a critical aspect of any kind of structuring, but the observations of different ways of structuring also bring to the fore that other aspects are critical. In the following we take a closer look at two distinctly different ways of combining instant finger patterns with counting.

\subsubsection{Counting on the unknown part on separate hand}

Nine children were found to create the parts $(3+5)$ on separate hands by both instantly creating one set on one hand and adding units on the other hand, until the whole is represented. A typical example of this can be found below. Oliver starts by creating the set of 3 and then continues counting on, on his other hand: "four, five, six, seven, eight". Since his whole hand is included in the counting on procedure, he gives a rapid answer: "Five" (see illustration in Fig. 2):

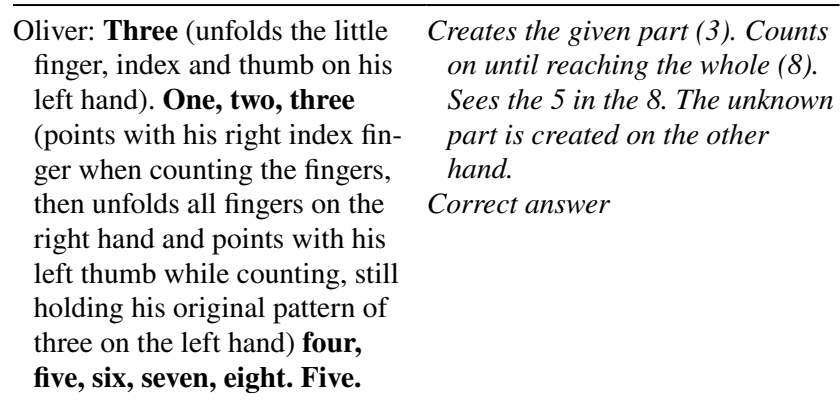

Seven of the nine children who enacted structuring in this way produced correct answers, which indicates that they experienced the first addend (3) as a composed set and kept track of the counted numbers until reaching the whole (8). Once having counted on to 8 , the children seemed to experience their finger pattern as a structure of the parts and the whole related to each other, and instantly recognized the unknown part (5). 

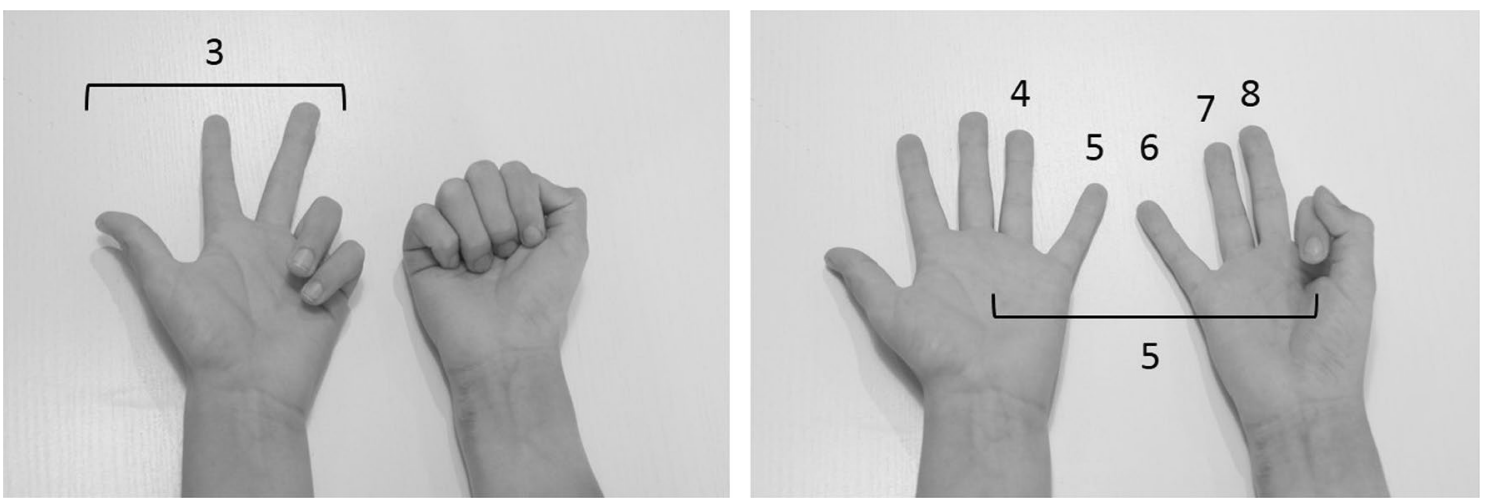

Fig. 3 Illustration of a child instantly showing the first part as a set (3), thereafter counting on on the same hand, and continuing to count on on the other hand to make 8 . The child sees "the 2" (fourth and fifth finger) and "the 3" (sixth, seventh and eighth finger) as one set of five

\subsubsection{Counting on by partitioning the unknown part on separate hands}

Composing sets can be done by counting and by instantly seeing a finger pattern, but the structuring can be enacted in yet another way than the one described above. Like most of the children, 12 of them started by creating the first given addend (3). However, like Mike in the excerpt below, they continued composing the whole (8) by counting their full hand $(3+2)$ and then continuing on the other hand $(+3)$. Some children then counted the missing part (one, two, three, four, five) or recognized the part instantly as 5 (see Fig. 3):

$\begin{gathered}\text { Mike: (Shows the thumb, index } \\ \text { and middle finger on his right }\end{gathered}$
$\begin{aligned} & \text { Creates the given part }(3) \\ & \text { Counts on until the whole is cre- } \\ & \text { hand, looks at his left hand }(8) .\end{aligned}$
(folded), then unfolds the ring
and little finger on his right
Counts the unknown part $(2+3)$ )
hand one at a time, then the $3+(2+3)$ in the 8.
thumb, index and middle finger
on his left hand. He then folds
the right hand's ring and little
fingers and unfolds them again,
then points with the right
thumb the unfolded fingers
on his left hand) Five more
glasses.

This way of solving the task seems to be a quite demanding act since the child has to experience, first of all, that the given part (3) is included in a part-part-whole relation with the 8 , and that the added fingers on his first hand (2) have to be added to the 3 on his other hand, leading to a structure in which the unknown part is partitioned into 2 and 3, yet constitutes a composite set of five. The children who started enumerating the missing part starting with 'one' (usually on the ring finger) succeeded and managed to see the 5 in the 8 (like Mike in the excerpt above). Some who started enumerating the whole (continuing from 'four') seemed to lose track of the parts, both given and unknown, as shown in the excerpt with Leah, below:

\begin{tabular}{|c|c|}
\hline $\begin{array}{l}\text { Leah: One, two, three (unfolds } \\
\text { three fingers, one at a time, } \\
\text { thumb, index and middle } \\
\text { finger, short pause) four, five } \\
\text { (unfolds ring and little finger) } \\
\text { six, seven, eight (thumb, index } \\
\text { and middle finger on her other } \\
\text { hand). I got two? (takes her } \\
\text { hands away) }\end{array}$ & $\begin{array}{l}\text { Creates the given part (3). Counts } \\
\text { single units to create the whole. } \\
\text { The unknown part is not differ- } \\
\text { entiated from the whole (8). } \\
\text { Discerns the part and the whole, } \\
\text { but loses the parts of the whole. } \\
\text { Incorrect answer }\end{array}$ \\
\hline $\begin{array}{l}\text { Interviewer: Hm. How many } \\
\text { glasses was it that you } \\
\text { needed to bring? }\end{array}$ & \\
\hline $\begin{array}{l}\text { Leah: Two glasses and I have } \\
\text { two children. }\end{array}$ & \\
\hline
\end{tabular}

Leah starts with the known part (3), and continuing to count on to make eight. However, she does not see the unknown part as differentiated from the whole. Instead she answers two, which could be interpreted as the remaining fingers of ten. Another plausible explanation could of course be that she does not fully understand the semantics of the task.

Structuring numbers in the task by partitioning the unknown part on separate hands illustrates to a larger extent the comprehensiveness of the part-part-whole relation, whereby the parts are included as a composite set of the whole. This differs from the earlier category (4.2.1), in which the whole was created and illustrated as two separate parts. Different ways of enacting a structural approach thus imply that different aspects are critical.

\subsection{Longitudinal findings}

When comparing the second and the third interview (conducted with a one year interval) we found a pattern in the 
Table 2 Changes in the children's enactment in interview III

\begin{tabular}{|c|c|c|c|c|}
\hline \multirow[t]{2}{*}{ Categories } & \multirow[t]{2}{*}{ Interview II $(n=28)$} & \multicolumn{3}{|l|}{ Interview III $(n=28)$} \\
\hline & & $\begin{array}{l}\text { Uncoordinated num- } \\
\text { bers, no answer }\end{array}$ & Structuring & Known number facts \\
\hline $\begin{array}{l}\text { 4.1 Instant separate } \\
\text { sets on two hands }\end{array}$ & 7 & $0(0 \%)$ & $6(86 \%)$ & $1(14 \%)$ \\
\hline $\begin{array}{l}\text { 4.2.1 Counting on the } \\
\text { unknown part on } \\
\text { separate hand }\end{array}$ & 9 & $4(44 \%)$ & $5(56 \%)$ & $0(0 \%)$ \\
\hline $\begin{array}{l}\text { 4.2.2 Counting on } \\
\text { by partitioning the } \\
\text { unknown part on } \\
\text { separate hands }\end{array}$ & 12 & $1(8 \%)$ & $8(67 \%)$ & $3(25 \%)$ \\
\hline
\end{tabular}

ways the children's enactment had changed (see Table 2). The sample is too small to take statistical measures and more tasks should be analyzed to make general statements about the findings, but there are tendencies in the children's enactment that are of educational interest.

Among the children who were counting on the unknown part as a set composed on the other hand (4.2.1), there were diverse results in the third interview in how they solved the same task. Two of the nine children in this category developed their way of seeing numbers as being composite sets which do not need to be counted (4.1), while three acted in similar structuring ways, creating sets using finger patterns and counting single units as 'counting on'. However, we also saw that three of these children enacted the more primitive strategy of 'counting all' or simply guessing in the later interview, which was a surprise. Solving the task by counting emphasized that the children experienced numbers as single units rather than composite sets structured in a part-part-whole fashion.

The third interview reveals that some ways of structuring seem to foster a continuation of using a structural approach while other ways of structuring seem not to facilitate the discernment of part-part-whole relations to the same extent, in this group of children. One explanation is that the structuring acts in interview II where children create parts and the whole on separate hands by counting on (4.2.1), may be an indication of the child experiencing local relationships; however this action does not seem to induce a generalization of their structuring. In contrast, when the children create the unknown part as partitioned on two hands but still constituting a composite set of five (4.2.2) they seem to experience the number relations differently, as they in the later interview enact in the same way (which by all means may be due to their discerning of the local relationship only, and having mastered this particular triad of numbers), or they have learnt the number relation as a fact and do not need to calculate or operate with the numbers to find the answer.

\section{Conclusion}

Two main categories of ways to structure the part-part-whole relation in an arithmetic task emerged in our observations: children who instantly create a finger pattern in which the numbers are experienced as part-part-whole relations; and children who instantly showed finger pattern sets and counted single units. The latter demanded a more thorough analysis, which revealed two significantly different ways of experiencing the numbers in the task with different outcomes for the development of arithmetic skills.

Based on our analysis we found one important difference in the category in which children both instantly showed finger pattern sets and counted to create the units in the task: the children used one or two hands to structure the unknown part. When separate hands were used to represent one part each, the child could concentrate on one part, then include it in the whole, and then differentiate the unknown part from the given part and see the ' 5 in the 8'. This way was sufficient for solving the task at hand and made the finger pattern of 8 and 5 easily recognized. However, seeing the enactment from a developmental perspective, it may not necessarily prepare children for seeing parts within parts, which is a useful skill when operating with larger numbers later and bridging through ten. Children using the separate hands approach solved the task correctly if they used the correct whole as their point of departure. We found that a few children structuring the task in this way did not take into account the correct whole (using 10 instead of 8 ) when solving the task, and even though they structured a part-part-whole relation on their fingers using finger patterns, they were consequently not able to solve the task as intended.

The second way identified was starting with the known addend (3), and adding 2 on the same hand and then 3 on the other hand to make 8 . We found that composing the unknown part by partitioning it on two hands was demanding for some children, as it is then necessary to perceive the parts in a part as well as the other part and the whole 
simultaneously. This way of structuring one part on two hands entails a composing-decomposing act, since the unknown part is partitioned but has to be experienced as one composite set as the answer. Most of these children succeeded in seeing 'the 5' even though it was composed of two and three on separate hands, whereas one child did not and answered "2", which could be interpreted as not seeing both the 2 and the 3 in the composition of 5, or as not taking the correct whole into account (10 instead of 8$)$. The enactment whereby children created a structure of number relationships, has the benefit of literally including the parts in the creation of the whole, which emphasizes the relation between the parts and the whole as necessary to be experienced simultaneously.

\section{Discussion}

The ability to interpret numbers as part-part-whole relationships has been argued to be of great importance in children's development of arithmetic skills (Resnick 1983). It makes it possible for the learner to create units of units, and see units within units and thereby solve addition and subtraction tasks in powerful ways. In our study we took a closer look at how children create units in a task with a part unknown. Earlier research by, e.g., Steffe and Cobb (1988) has suggested that counting strategies in which children add single units do not facilitate their seeing counted steps as a composite part of number. Counting approaches thereby do not necessarily prepare or induce children to experience the part-part-whole relations of numbers. Nevertheless, most of the children in our study did enact some kind of counting. From a variation theory perspective, different ways of acting in an arithmetic problem solving situation, or in our case different ways of creating sets in a task, are grounded in different ways of seeing numbers. This means that there can be more to understanding arithmetic skills development than merely studying what strategies (counting or structuring) a child has learned (cf. Cheng 2012).

Marton and Neuman (1990) also identified strategies that seven-year-old children used when solving the same type of task as in this paper $\left(\mathrm{a}+_{-}=\mathrm{c}\right)$. However, we add new knowledge to the study of Marton and Neuman (1990) by showing in greater detail how five-to-six-year-old children enacted their structuring of numbers on their fingers, of which some ways can be considered more powerful than others when considering the three critical aspects identified that children need to discern in order to structure the task. One critical aspect, we suggest, is that the whole needs to be discerned, since we found that some children lost track of the whole while trying to identify the missing part. Furthermore, children need to see (experience) the parts within the whole, meaning that numbers are related to each other in a triad manner. A third critical aspect is the recognition of finger patterns as a representation of the cardinality of a set, since this enables them to structure the part-part-whole relation of the task. If children experience these aspects when encountering the arithmetic task, we suggest, they have discerned emergent structures of local relationships (see Venkat et al. 2019).

Ways of structuring are complex acts to observe and interpret. Baroody et al. (1983) stated already that the use of the part-whole relations may very well be localized to a limited number of cases. In our task 'the whole hand' may thus constitute a learned fact that works well for the particular task $3+_{-}=8$ and could be expressed as creating the missing part separately from the given part (category 4.2.1), but the child may not be as sure of the part-whole relations in other numerical combinations. This, as we see it, would according to Venkat et al. (2019) be an example of (emergent) structure, an awareness of local relationships, which in turn is a foundation for attending to generalized mathematical relationships.

Based on the close investigation of how children structure part-part-whole relations, we further suggest that those children who composed the unknown part as counting on partitioned on both hands $(2+3)$ opened up the possibility of also discerning the more general mathematical properties of decomposition strategies. Thus the enactment demands that they see the parts related to each other and the whole and how one part can be de-composed to fit the structure (finger pattern representing the whole) at the same time. This simultaneous awareness of the necessary aspects of the task at hand would according to variation theory be an example of a more powerful way of experiencing numbers and thus promote further conceptual development, to which the third interview also has given some credence.

\section{Future research}

In this study we analyzed data mainly from the second interview (of three). The third interview, conducted one year after the second one, showed that all children who partitioned the unknown part on their two hands further developed their enactment (compared with those who counted on separate hand). These children all enacted the same successful way of structuring in the third interview, thus not counting at all but rather seeing the parts and the whole as finger pattern sets, or having developed known number facts from which they drew when solving the same task. This was also true among those who did not figure out the correct answer in the second interview but used the same strategy. All the children in our study who had instantly structured the numbers on their fingers without counting at all continued to structure in a similar way or 
retrieve from known facts in the third interview. Thus, experiencing numbers as composite sets seem important and robust for attending to the numbers' part-whole relations in arithmetic tasks. That said, the findings strongly indicate the importance of direct attention not only to the fact that children structure numbers, but that how they structure, or rather how they experience the number relations within the structured finger patterns, may have a significant impact on their future development of arithmetic skills. Further research with a larger sample and multiple tasks is needed to study how children over time understand number relations, and how interventions can enhance development.

\subsection{Implications for practice}

Deeper knowledge about children's ways of understanding and using numbers are known to inform teachers' practice. In our investigation of children's ways of structuring we revealed that there are differences in enactment, and also in the power of the enactments. The differences found have been interpreted depending on what aspects were discerned, some of which are critical for further more advanced arithmetic problem solving but not necessarily for the task at hand; that is, children sometimes structure in order to create units, for example by partitioning the parts on two hands, even though the task could be more easily solved by creating parts on separate hands. The former strategy may be seen as an expression of a more advanced way of experiencing numbers, which will be necessary, for example, when encountering a larger number range and bridging through 10 (cf. Hatano 1982). However, for some children in our study it entailed complications, since more aspects have to be discerned simultaneously for enacting the de-composing strategy. Based on these findings and conclusions, teachers thus need to pay attention to how children create units, and whether they experience the relation between the parts and the whole while creating the units. Finger patterns seem to be helpful in representing relations between numbers, but it is also critical that the child identifies what constitute the parts and the whole. This means that children should not foremost be taught to use certain strategies and structural approaches, but to understand the number relations they are creating while structuring. To confirm this conclusion and further develop education in the early years, intervention studies are needed aiming at developing children's way of experiencing numbers as part-whole relations.

Acknowledgements Open access funding provided by University of Gothenburg. This study was funded by the Swedish Research Council (Vetenskapsrådet, Grant no. 721-2014-1791).
Open Access This article is licensed under a Creative Commons Attribution 4.0 International License, which permits use, sharing, adaptation, distribution and reproduction in any medium or format, as long as you give appropriate credit to the original author(s) and the source, provide a link to the Creative Commons licence, and indicate if changes were made. The images or other third party material in this article are included in the article's Creative Commons licence, unless indicated otherwise in a credit line to the material. If material is not included in the article's Creative Commons licence and your intended use is not permitted by statutory regulation or exceeds the permitted use, you will need to obtain permission directly from the copyright holder. To view a copy of this licence, visit http://creativecommons.org/licenses/by/4.0/.

\section{References}

Ahlberg, A. (1997). Children's ways of handling and experiencing numbers. Gothenburg: Acta Universitatis Gothoburgensis.

Baroody, A., \& Purpura, D. (2017). Early number and operations: Whole numbers. In J. Cai (Ed.), Compendium for research in mathematics education (pp. 308-354). Reston: National Council of Teachers of Mathematics.

Baroody, A., Ginsburg, H., \& Waxman, B. (1983). Children's use of mathematical structure. Journal for Research in Mathematics Education, 14(3), 156-168.

Bender, A., \& Beller, S. (2012). Nature and culture of finger counting: Diversity and representational effects of an embodied cognitive tool. Cognition, 124(2), 156-182.

Berteletti, I., \& Booth, J. R. (2015). Perceiving fingers in single-digit arithmetic problems. Frontiers in Psychology, 6(226), 1-10.

Björklund, C., \& Runesson Kempe, U. (2019). Framework for analysing children's ways of experiencing numbers (pp. 6-10). Utrecht: Proceedings from CERME.

Björklund, C., Kullberg, A., \& Runesson Kempe, U. (2019). Structuring versus counting - Critical ways of using fingers in subtraction. ZDM, 51(1), 13-24.

Carpenter, T. P., \& Moser, J. M. (1982). The development of addition and subtraction problem-solving skills. In T. P. Carpenter, J. M. Moser, \& T. A. Romberg (Eds.), Addition and subtraction: A cognitive perspective (pp. 9-24). Hillsdale: Lawrence Erlbaum.

Carpenter, T. P., \& Moser, J. M. (1983). The acquisition of addition and subtraction concepts. In R. Lesh \& M. Landau (Eds.), Acquisition of mathematics concepts and processes (pp. 7-44). New York: Academic.

Cheng, Z. J. (2012). Teaching young children decomposition strategies to solve addition problems: An experimental study. The Journal of Mathematical Behavior, 31(1), 29-47.

Clements, D. H., Sarama, J., \& MacDonald, B. L. (2019). Subitizing: The neglected quantifier. In A. Norton, M. W. Alibali (Eds.), Constructing number. Research in Mathematics Education (pp. 13-46).

Crollen, V., Seron, X., \& Noël, M.-P. (2011). Is finger-counting necessary for the development of arithmetic abilities? Frontiers in Psychology, 2(242), 1-3. https://doi.org/10.3389/fpsyg.2011.00242.

Davydov, V. V. (1982). The psychological characteristics of the formation of elementary mathematical operations in children. In T. P. Carpenter, J. M. Moser, \& T. A. Romberg (Eds.), Addition and subtraction: A cognitive perspective (pp. 224-238). Hillsdale: Lawrence Erlbaum.

Fuson, K. (1982). An analysis of the counting-on solution procedure in addition. In T. P. Carpenter, J. M. Moser, \& T. A. Romberg (Eds.), Addition and subtraction: A cognitive perspective (pp. 67-81). Hillsdale: Lawrence Erlbaum.

Fuson, K. (1988). Children's counting and concepts of number. New York: Springer. 
Fuson, K. (1992). Research on whole number addition and subtraction. In D. A. Grouws (Ed.), Handbook of research on mathematics teaching and learning (pp. 243-275). New York: Macmillan.

Geary, D. C., Hoard, M. K., Nugent, L., \& Baily, D. H. (2013). Adolescents' functional numeracy is predicted by their school entry number system knowledge. PLOS ONE, 8(1), 1-8.

Hatano, G. (1982). Learning to add and subtract: A Japanese perspective. In T. P. Carpenter, J. M. Moser, \& T. A. Romberg (Eds.), Addition and subtraction: A cognitive perspective (pp. 211-223). Hillsdale: Lawrence Erlbaum.

Hunting, R. P. (2003). Part-whole number knowledge in preschool children. Journal of Mathematical Behaviour, 22(3), 217-235.

Ifrah, G. (1985). From one to zero: A universal history of numbers. New York: Viking Penguin.

Lüken, M. (2012). Young children's structure sense. Journal für Mathematik-Didaktik, 33(2), 263-285.

Marton, F. (1981). Phenomenography-Describing conceptions of the world around us. Instructional Science, 10(2), 177-200.

Marton, F. (2015). Necessary conditions of learning. New York: Routledge.

Marton, F., \& Booth, S. (1997). Learning and awareness. Mahwah: Lawrence Erlbaum.

Marton, F., \& Neuman, D. (1990). Constructivism, phenomenology, and the origin of arithmetic skills. In L. P. Steffe, \& T. Wood (Eds.) Transforming children's mathematics education: International perspectives. Hillsdale: Lawrence Erlbaum.

Marton, F., \& Neuman, D. (1996). Phenomenography and children's experience of division. In L. P. Steffe, P. Nesher, P. Cobb, G. A. Goldin, \& B. Greer (Eds.), Theories of mathematical learning (pp. 315-335). Mahwah: Lawrence Erlbaum.

Mason, J., Stephens, M., \& Watson, A. (2009). Appreciating mathematical structure for all. Mathematics Education Research Journal, 21(2), 10-32.

Mulligan, J. T., \& Mitchelmore, M. (2009). Awareness of pattern and structure in early mathematical development. Mathematics Education Research Journal, 21(2), 33-49.

Neuman, D. (1987). The origin of arithmetic skills: A phenomenographic approach. Göteborg: Acta Universitatis Gothoburgensis.
Neuman, D. (2013). Att ändra arbetssätt och kultur inom den inledande aritmetikundervisningen (Changing the culture and ways of working in early arithmetic teaching). Nordic Studies in Mathematics Education, 18(2), 3-46.

Reeve, R., \& Humberstone, J. (2011). Five- to 7-year-olds' finger gnosia and calculation abilities. Frontiers in Psychology, 2(359), 1-10. https://doi.org/10.3389/fpsyg.2011.00359.

Resnick, L. B. (1983). A developmental theory of number understanding. In H. Ginsburg (Ed.), The development of mathematical thinking (pp. 109-151). New York: Academic Press.

Schmittau, J. (2003). Cultural-historical theory and mathematics education. In A. Kozulin, B. Gindis, V. S. Ageyev, \& S. M. Miller (Eds.), Vygotsky's educational theory in cultural context (pp. 225-245). Cambridge: Cambridge University Press.

Sinclair, N., \& Pimm, D. (2015). Mathematics using multiple senses: Developing finger gnosis with three- and four-year-olds in an era of multi-touch technologies. Asia-Pacific Journal of Research in Early Childhood Education, 9(3), 99-110.

Steffe, L. P. (1994). Children's multiplying schemes. In G. Harel \& J. Confrey (Eds.), The development of multiplicative reasoning in the learning of mathematics (pp. 3-40). New York: State University of New York.

Steffe, L. P., \& Cobb, P. (1988). Construction of arithmetical meanings and strategies. New York: Springer.

Venkat, H., Askew, M., Watson, A., \& Mason, J. (2019). Architecture of mathematical structure. For the Learning of Mathematics, 39(1), 13-17.

Verschaffel, L., Greer, B., \& De Corte, E. (2007). Whole number concepts and operations. In F. K. Lester (Ed.), Second handbook of research on mathematics teaching and learning (pp. 557-628). Charlotte: Information Age.

Publisher's Note Springer Nature remains neutral with regard to jurisdictional claims in published maps and institutional affiliations. 